\title{
Microstructural Characterization on AISI 4140 Steel Boriding by New and Reused Dehydrated Boron Paste
}

Noe Lopez Perrusquia ${ }^{1}$, Marco Doñu Ruiz², Ernesto Garcia Bustos ${ }^{3}$, Christopher René Torres San Miguel $^{4}$ and Victor Olmos Domínguez ${ }^{5}$

${ }^{1}$ Universidad Politecnica del Valle de México, Mexico, Distrito Federal, Mexico, ${ }^{2}$ Universidad Politécnica del Valle de México, Tultitlan, Distrito Federal, Mexico, ${ }^{3}$ Universidad de Guadalajara, Mexico, Jalisco, Mexico, ${ }^{4}$ Instituto Politécnico Nacional, Ciudad de Mexico, Distrito Federal, Mexico, ${ }^{5}$ Universidad Tecnológica de México, Estado de México, Distrito Federal, Mexico

Boriding is a process of surface hardening; it is utilized on ferrous and non-ferrous metallic materials for possible industrial applications [1]. The different studies of microstructural and surface characterization show the benefits of the $\mathrm{Fe}_{2} \mathrm{~B}$ phase and/or the $\mathrm{FeB} / \mathrm{Fe}_{2} \mathrm{~B}$ phases obtained by the boriding processes $[2,3]$. Thus the common point of the researchers is to obtain a $\mathrm{Fe}_{2} \mathrm{~B}$ monolayer, the less brittle for industrial applications and for manufacturing engineering [4].

The study is using AISI 4140 steel, with a chemical composition of $0.40 \% \mathrm{C}, 0.80 \% \mathrm{Mn}, 0.25 \% \mathrm{Si}, 1.00 \%$ $\mathrm{Cr}, 0.20 \% \mathrm{Mo}, 0.04 \% \mathrm{~S}$ and $0.035 \%$ P. Specimens for surface treatment have dimensions of 1.5 inches of diameter and 0.32 high. The formation of iron boride was formed at a temperature of $900^{\circ} \mathrm{C}$, with an exposure time of $8 \mathrm{~h}$; using the process of pack boriding with new and reused dehydrated boron paste; using a conventional muffle without inert gas. The surface microstructure was studied by Optical Microscopy (OM) using ZEISS Axio Vert.A1, in addition the phases of boride iron are identified by XRay Diffraction (XRD) with equipment Bruker D8 Advance, Cu radiation K $\alpha \lambda=1.5406 \AA$ and hardness using an Ultra Micro Hardness Tester Mitutoyo; indentation load to $100 \mathrm{mN}$. The adhesion of layer boride on the surface was determined by the Daimler-Benz Rockwell-C test, norm VDI 3198; using a Scanning Electron Microscopy (SEM), Bruker D8 Advance.

Figure 1a) shows the $\mathrm{Fe}_{2} \mathrm{~B}$ layer, obtained by reused dehydrated boron paste, The layer shows not uniform morphology of the saw-tooth, with a thickness of $79.91 \mu \mathrm{m} \pm 20.61$ also with a hardness of $1799.12 \mathrm{HV} \pm$ 35.23.The results by XDR show the $\mathrm{Fe}_{2} \mathrm{~B}$ layer on the surface of AISI 4140 steel. Figure 1b) with new dehydrated boron paste shows an thickness $128.23 \mu \mathrm{m} \pm 25.32$ and hardness $2013 \mathrm{HV} \pm 20.02$ on $\mathrm{FeB} / \mathrm{Fe}_{2} \mathrm{~B}$ layers; has a homogeneous layer of saw-tooth and XRD evidences the formation on the surface of $\mathrm{FeB} / \mathrm{Fe}_{2} \mathrm{~B}$ layers on AISI 4140 steel.Figure 2 shows the images by SEM to evaluate the layer quality and the adhesive resistance of the indentation marks on the surface of AISI 4140 boriding steel with new and reused dehydrated boron paste. Figure 2a) by SEM shows a small amount of cracks generating adhesion $\mathrm{HF} 1$ caused by the formation of the $\mathrm{Fe}_{2} \mathrm{~B}$ layer. Figure $2 \mathrm{~b}$ ) shows by SEM an increase in cracks caused by the formation of the $\mathrm{FeB} / \mathrm{Fe}_{2} \mathrm{~B}$ layers showing adhesion $\mathrm{HF}$. radial cracks, circumferential cracks and partial delamination or flaking are observed on the perimeter of the indentation craters, caused by the presence of FeB layer obtained using new dehydrated boron paste. In comparison, there are less cracks, circumferential cracks and small delamination or flaking in the indentation mark as a result of the presence of the $\mathrm{Fe}_{2} \mathrm{~B}$ layer generated by reused dehydrated boron paste; The quality of the adhesion resistance of the $\mathrm{Fe}_{2} \mathrm{~B}$ layer is acceptable. It was demonstrated the effect of the boriding process by dehydrated boron paste new and reused, to obtain a type layer of iron boride, different morphology of saw-tooth and 
transformation of hardness. Likewise, it is deduced that the presence of the $\mathrm{Fe}_{2} \mathrm{~B}$ monolayer is adequate to obtain a better quality of adhesion resistance.

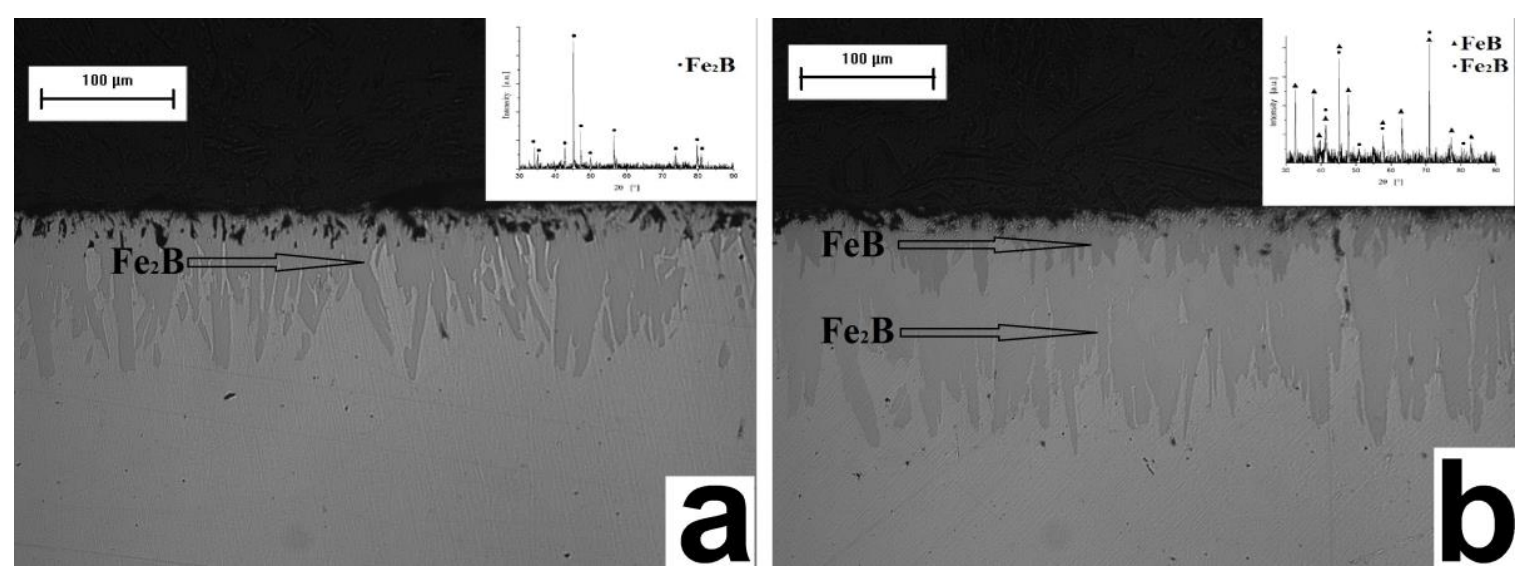

Figure 1. Optical micrographs of the layer formed on the surface and XRD diffraction patterns; a) reused dehydrated boron paste and (b) new dehydrated boron paste
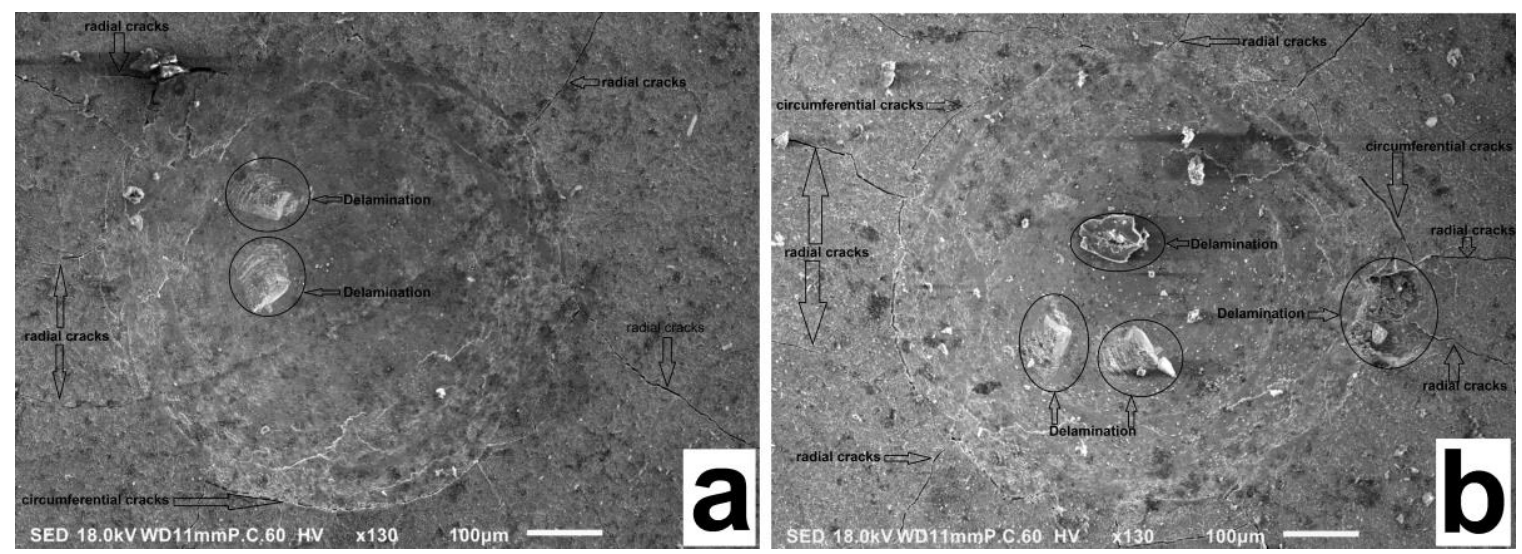

Figure 2. SEM micrographs of VDI adhesion test on; (a) reused dehydrated boron paste and (b) new dehydrated boron paste

\section{References}

[1] Kulka M. Trends in Thermochemical Techniques of Boriding. In: Current Trends in Boriding. Engineering Materials. Springer, (2018), p 17-98.

[2]G.J. Pérez Mendoza, et. al . Microscopy and Microanalysis, 25(S2) (2019), p.2398-2399.

[3]M. Ortiz-Domínguez, et.al . Microscopy and Microanalysis, 25(S2) (2019), p.2652-2653

[4] İlyas Türkmen, et. al, Surf. and Coat. Techn. 377, (2019), p. 124888. 